\title{
Developing and Using Multiple Models to Promote Scientific Literacy in the Context of Socio-Scientific Issues
}

\author{
Li Ke $^{1}$ (D) Troy D. Sadler $^{1}$ (D) $\cdot$ Laura Zangori $^{2}$ (D) Patricia J. Friedrichsen ${ }^{2}$ (D)
}

Accepted: 17 February 2021 / Published online: 6 April 2021

(c) The Author(s), under exclusive licence to Springer Nature B.V. 2021

\begin{abstract}
Learning science in the context of socio-scientific issues (SSI) can promote scientific literacy that links science to everyday life and society. In this position paper, we argue that developing and using multiple models equip students with the appropriate knowledge and skills needed to deal with complex issues. We draw upon literature from science education and philosophy of science and advance our theoretical argument about why it is critical for students to develop and use multiple models as part of their science learning experiences in general, and how the practice benefits students in the context of SSI in particular. We posit that students should engage in both scientific and socio-scientific models as they explore a complex societal issue because (1) engagement in multiple scientific models promotes students' understanding about the phenomena relevant to the focal issue, and (2) engagement in socio-scientific models helps students to use that scientific knowledge in the larger social contexts and reason about how interacting science and social factors may impact students' positions on the complex issue. We take COVID-19 as the learning context and present exemplar models students can develop and use as they learn about the pandemic. We conclude the paper by discussing the teaching aspects of the proposed modeling approach for SSI-based instruction as well as identifying possible areas for future research.
\end{abstract}

COVID-19 is sweeping across the world and changing everyone's life in an unprecedented way. The challenging situation we are experiencing demands scientific literacy for all (DeBoer, 2000), now more than ever, so that we can act appropriately in response to the pandemic as responsible citizens. This is of particular relevance to science educators because of the role of school-based instruction for promoting scientific literacy among youngsters. Indeed, scientific literacy has been framed as the overarching goal for science education for decades (AAAS, 1993; Laugksch, 2000; Sadler \& Zeidler, 2009). Yet, what counts as scientific literacy remains ambiguous as the construct has been variedly interpreted under different circumstances, ranging from an explicit focus on emulating professional practices in the science disciplines to a sociocultural-centered approach (Brown

$\mathrm{Li} \mathrm{Ke}$

lke@unc.edu

1 School of Education, University of North Carolina at Chapel Hill, Chapel Hill, NC, USA

2 Department of Learning, Teaching, and Curriculum, College of Education, University of Missouri, Columbia, MO, USA 
et al., 2005) that situates science learning in the context of everyday life. For the purpose of this paper, we define scientific literacy as a functional understanding of science including, but not limited to, (1) content knowledge consistent with those of the scientific community, (2) understanding of how science works, (3) a sense of what counts as evidence and how to interpret it, and (4) recognition of how science connects to the social dimensions of the world. Our conceptualization of scientific literacy aligns with what Roberts (2007) called a Vision II scientific literacy that highlights the use of science to inform decisions in daily lives.

Over the last two decades, research on science learning in the context of socio-scientific issues (SSI) has proven effective in promoting scientific literacy. SSI are complex, ill-defined societal issues that have a basis in science such as climate change. SSI-based instruction requires students to not only consider the science dimension, but also the social ramifications of the issue in order to develop positions or solutions around the issue (Sadler et al., 2019; Zeidler et al., 2005). Prior research indicates that, with appropriate curricular and instructional supports, SSI-based instruction can promote students' proficiencies in disciplinary knowledge and practices, reasoning skills, and ideas about the nature of science (see the review by Zeidler, 2014). In addition, our team's recent work suggests that engaging students in disciplinary practices such as modeling can productively influence students' negotiation of complex issues (Peel et al., 2019; Zangori et al., 2017).

While modeling is in itself an important topic in science education and has been studied extensively (see the review by Louca \& Zacharia, 2012), it has not been investigated systematically in the context of SSI until recently. We argue that integrating modeling and SSI learning has great potential for achieving the goal of scientific literacy as the practice of modeling can be mutually supportive of SSI learning (Ke at al., 2020b). On one hand, SSI provides a meaningful context for modeling practice that is relevant to students' lives. On the other hand, developing and using models can foster robust understanding of the underlying science phenomena (Manz, 2012; Passmore et al., 2014; Windschitl et al., 2008; Zangori \& Forbes, 2014) necessary for negotiating the related issues. However, considerably less is known about how and why the integration can work as an effective approach for SSI learning. For instance, what do students gain by engaging in modeling as they explore and negotiate complex societal issues? What aspects of modeling activities are essential for influencing students' positions or reasoning about the issues? In this paper, we advance this line of inquiry related to incorporating modeling practice with SSI-based instruction. In particular, we posit that developing and using multiple models can promote scientific literacy by equipping students with the appropriate knowledge and skills needed to deal with complex societal issues such as COVID-19. While our proposal for incorporating multiple models addresses all four aspects of the functional scientific literacy we defined earlier, we mainly center our arguments around canonical scientific knowledge and its social implication in this paper.

It is important to note at the outset that multiple models are not the same as multiple representations. Consider, for example, the gas law. While the gas law can be represented in many forms such as a mathematical equation, a diagram, or a graph, and each form by itself can be viewed as a model, these forms taken together cannot be conceived as different or multiple models. This is because all these different forms are representing the same variables and the relationships in an attempt to account for the behaviors of gases. In other words, these forms are different representational modes of a single model for gas properties (i.e., the gas law). As shown in this example, all models entail two levels of representation (Knuuttila, 2005). While the first level is concerned with choosing relevant attributes to represent certain aspects of the target phenomena or systems for particular aims, the 
second level is about selecting appropriate material forms to represent those attributes. In this paper, we explore the idea of developing and using multiple models in the context of SSI learning with a focus on the first level of representation. This focus is distinct from prior research efforts on multiple representations that primarily attend to the second level of representation and examine how students navigate among different representational modes for complex science concepts or experiments (Ainsworth, 2008; Stieff et al., 2016). While we know much about the affordances of using multiple representational modes for science teaching, our theoretical argument contributes new knowledge to the field by highlighting how developing and using multiple models could foster representational competencies in characterizing different features of the underlying phenomena or systems, and in turn promote scientific literacy.

In the following sections, we first put forward our theoretical argument about why it is critical for students to develop and use multiple models in SSI-based learning. We then describe in detail the two types of modeling activities students should engage as they explore an issue. Next we take COVID-19 as a learning context and present exemplar models students can develop and use as they learn about the pandemic. We conclude the paper by discussing the teaching aspects of the proposed modeling approach for SSI-based instruction as well as identifying possible areas for future research.

\section{Rationale}

In this section, we provide our rationale for developing and using multiple models in SSIbased learning. We begin with a review of the literature concerning the multiplicity of models to answer the question: why is it important for students to develop and use multiple models as part of their science learning experience in general? The review aims to serve as the basis for our argument associated with developing and using multiple models in the context of SSI.

The use of models as a pedagogical tool has long been documented in school-based science instruction (see Gilbert \& Osborne, 1980). Using models in teaching has gained much traction over the past decades as recent reform efforts in science education (Duschl et al., 2007; National Research Council, 2012) increasingly call for students' appropriation of core disciplinary practices such as modeling. Models are simplified representations that can explain and predict phenomena or systems under study (Lehrer \& Schauble, 2006; Schwarz et al., 2009). Models can take a variety of forms, including drawings, diagrams, mathematical equations, physical objects, computer simulations, and so forth. Modeling is the practice of creating, revising, evaluating, and using models; at the heart of these activities is knowledge building (Nersessian, 2008). Hence, modeling practice is epistemic in nature and requires simplifying reality for particular purposes. This simplification process involves (1) deciding on the appropriate form a model is based upon, (2) choosing the relevant components or variables to include in a model, and (3) organizing the interacting components in a way that represents the key features of the phenomena or system at stake. Learners need to engage in all three parts to realize the intended epistemic goals. Therefore, all models have limitations, and they are always partial in the sense that a model only represents certain aspects of phenomena or systems for certain epistemic purposes. In other words, there is no simple one-to-one relationship between models and the reality. Rather, according to Cartwright (1999), reality is covered by a "patchwork" of models, with gaps 
in between an array of overlapping patches of different sizes and shapes. The metaphor suggests that multiple models with different aims provide a more complete account of the phenomenon or system than a single model does.

While this may sound intuitive, formulating multiple models is indeed a necessity rather than a luxury in scientific research traditions. Scientists frequently resort to diverse models since a particular model often cannot meet all desired criteria (e.g., generality, realism, precision) simultaneously. For instance, a model focusing on a specific case can produce precise and reliable results based on accurate measurement and realistic parameter setting, but its application to other related cases is probably limited. As ecologist Richard Levins (1966) argues in his seminal work on model building in population biology, formulating multiple models can manage such trade-off, especially for highly complex phenomena or systems. Weisberg (2007) further develops this idea and contends that formulating multiple models is a critical form of idealization (i.e., the intentional introduction of distortion into scientific theories) that plays an important role in scientific inquiry and theory formation. Taken together, a cluster of related but different models contribute to a more complete understanding of the phenomena of interest.

Given the prevalence of multiple models for the exploration of complex science ideas and systems, it is sensible for students to develop and use multiple models in some parallel form that are meaningful for classroom knowledge-building communities. In particular, we argue that it is of critical value that students are able to recognize the merits and limitations of different models and use them to collectively account for the phenomena or systems. In this way, students can develop a "grasp of practice" (Ford, 2008) regarding how scientists contemplate the epistemological trade-offs among multiple models. This line of thinking has emerged sporadically from the modeling literature as scholars weigh in on how multiple models may benefit student learning in school contexts (Frederiksen \& White, 2002; Oh \& Oh, 2011). For instance, Lehrer and Schauble (2012) theorize that, through developing and using multiple models, students are able to make sense of the natural world in a similar way as their counterparts in the discipline:

Professional scientists use representational systems and models at all levels, so our aim is not to replace physical models with more sophisticated representations. Instead, the point is to equip students with a repertoire of representations and models that can be used to build layers of description, each showcasing something different about the phenomenon being modeled...Ultimately, the models "circulate" (Latour, 1999) and "interlock" (Nersessian, 2008), resulting in a representational system that enhances children's theories of the natural world. (p. 703)

Furthermore, prior work on a learning progression of modeling (Schwarz et al., 2009) sheds light on how multiple models might be introduced to science classrooms. In particular, in the proposed learning progression, "students construct and use multiple models to explain and predict more aspects of a group of related phenomena" (level 3) is viewed as a more sophisticated practice than "students construct and use a model to illustrate and explain how a phenomenon occurs" (level 2). As such, it might make more sense for students to start with working on a single model to get a handle of how models function to explain and predict phenomena. Once students realize the limitations of their models in explaining or predicting phenomena, there is a need for them to develop alternative or multiple models to better account for the target phenomena or systems. Consistent with this notion of progression, the Next Generation of Science Standards (NGSS; Lead States, 2013 ) in the USA has identified navigating between multiple models as one of the ultimate learning goals related to modeling practice. High school students are expected to "develop 
and/or use multiple types of models to provide mechanistic accounts and/or predict phenomena, and move flexibly between model types based on merits and limitations." It is important to note that the proposed placement in high school by the NGSS does not necessarily mean that young learners are incapable of participating in this complex practice. Rather, it illustrates the point that developing and using multiple models needs to be gradually built in a coherent manner.

So far, we have discussed how developing and using multiple models exemplifies scientists' work in the discipline and can therefore help students "see" how science works in classrooms settings. Next we justify how the practice can be particularly productive in promoting students' scientific literacy through SSI learning. While a parallel argument can be made about the suitability of modeling in science classrooms with an emphasis on the authenticity of the practice, there are additional motivations for engaging students in developing and using multiple models in the context of SSI. First, as we discussed earlier, a key aspect of modeling practice is to recognize the limitations of different models. In order to do so, students must look closely into the assumptions or approximations made in the process of simplifying real-world situations and examining how well a proposed model may apply to other new or unverified contexts. This practice fits well with SSI learning as most issues involve aspects of the science dimension that are new and cannot be well explained by the existing scientific understanding (Kolst $\varnothing, 2001$ ). By developing and using different models to account for the underlying science associated with the issue, students become cognizant of the limitations of science in resolving complex societal issues. The notion that science alone cannot offer solutions to issues is important for students to grapple with as they reason about controversial societal issues (Sadler et al., 2017).

Second, developing and using multiple models can coordinate and enhance students' scientific understanding about different scientific phenomena embedded in an SSI. Unlike traditional science learning, learning science in the context of SSI often involves exploring different phenomena or systems at the same time, thus providing students with opportunities to develop and use multiple models. It is important to note that here students are developing and using multiple models for different phenomena relevant for the same issue, as opposed to doing so for the same phenomenon as we discussed earlier. Consider, for instance, the issue of fracking. The science dimension of fracking is not centered around a focal phenomenon such as the particulate nature of matter. Instead, the issue deals with a cluster of scientific ideas and phenomena including the process of hydrofracturing, resource cycling, greenhouse gas emissions, and long-term effects of inhaled pollutants on the human body. In order to formulate informed decisions on the issue, students must develop understandings of not just a single phenomenon, but rather multiple dimensions of science associated with the issue. We posit that developing and using multiple models to explain those phenomena can be a productive way to achieve this goal.

Third, students need to take into consideration the whole issue-related system comprising both science and social dimensions so that they can appreciate the complexity of the issue (Sadler et al., 2007). This calls for unique modeling opportunities as the relationships among key factors within and across dimensions can be particularly challenging for students to navigate (Ke et al., 2020a). Moreover, the type of models used to illustrate, explain, and predict the behaviors of the system encompassing both science and social dimensions (we refer to this as socio-scientific modeling hereafter) differs from those that solely account for phenomena within the science domain. Socio-scientific models allow students to make connections among relevant social, political, and economic factors that can play key roles in decision-making about the focal issue. It is important to recognize that evidentiary criteria for positioning social, political, and economic factors within a 
socio-scientific model are necessarily different from the evidence used to substantiate a scientific model (or the positioning of scientific factors within a socio-scientific model) (Jimenez-Aleixandre, 2002). Additionally, people tend to use anecdotal evidence such as personal narrative when engaged in argumentation around socio-scientific issues (Levinson, 2008; Sadler, 2004). Therefore, the nature of evidence used to justify the relationships among key components and the reasoning patterns exhibited in socio-scientific models are qualitatively different from those in typical scientific models. Despite the differences, we contend that the two types of models can be used in service of each other and are critical for students' developing positions on the issue, which we elaborate more in the next section.

\section{Different Types of Models}

We have previously discussed that developing and using multiple models can be a powerful strategy for SSI learning. Here we further argue that productive SSI learning should engage students in multiple modeling activities that serve the following two purposes: (1) to understand the science aspects of the phenomena and systems underlying the issue, and (2) to understand the complexity of the issue by taking into account not only the science dimension, but also the social and political dimensions of the issue. As such, we find it helpful to group models into two broad categories, scientific models and socio-scientific models respectively, so that they align with these two purposes. The point of the distinction is to make explicit the epistemic aims (Chinn et al., 2011) of different models that students can develop and use in the context of SSI learning. In this way, modeling activities can be intentionally designed to support students' negotiations of complex societal issues. Below we describe in detail the characteristics of these two types of model as well as the connections between them.

\section{Scientific Models}

Most models referenced in the science education literature are scientific models that function to explain and predict scientific phenomena or systems. Under the umbrella of scientific models, researchers have attempted to further categorize models (see Harrison \& Treagust, 2000; Clement, 2008) based on a variety of features including representational modes (e.g., diagrams, equations, graphs), epistemic aims (explanatory models vs. predictive models), and computational approaches (systems dynamics models vs. agent-based models). Yet, the field has yet to arrive at a consensus typology of scientific models, in part because models are multifaceted in nature and each categorization method is limited in featuring certain aspects of underlying phenomena or systems. As a result, little is known about how the use of models with distinct features may differ in representing, explaining, and predicting the same phenomena. Neither do we know much about what types of models might be more appropriate for students to develop and use for what topics and epistemic purposes. This can be particularly challenging for teachers who are expected to enact modeling practice throughout the science curriculum with diverse scientific topics. To address the issue, we next briefly describe the characteristics of three types of scientific model, 
namely (1) mechanistic models, (2) system models, and (3) mathematical/data models, and highlight the affordances of these models under various learning contexts.

\subsection{Mechanistic models}

One predominant type of scientific model in science education contexts is mechanistic models that aim to explain how and why phenomena occur (Forbes et al., 2015; Ke \& Schwarz 2021; Gray \& Rogan-Klyve, 2018). In contrast to phenomenological models (Bokulich, 2011) that are highly predictive, but primarily represent observable properties of the target phenomena (e.g., climate models), mechanistic models are powerful for unraveling the hidden mechanisms of the phenomena and often involve causal step-by-step processes beyond the observable scale. For example, a drawing about how light travels (e.g., in a straight line from a light source towards an object, and then bounces back to one's eyes) is a mechanistic model that can explain a range of phenomena related to how we see things (see Krajcik et al., 2012). In science classrooms, a mechanistic model often takes the form of a drawing that students create from scratch primarily based on their existing knowledge and personal experience. Compared to other model types of which students are not allowed to manipulate the basic structures (e.g., computer simulation or pre-programmed computational models), mechanistic models have an advantage in giving students ownership of their models and promoting epistemic agency (Stroupe, 2014) because they help students build their own knowledge products. Additionally, mechanistic models are often developed through iterative processes of model construction, revision, and evaluation as students gain additional evidence and knowledge about the phenomena. It is through these iterative processes that students shift from naïve understandings about the phenomena towards more sophisticated explanatory accounts that link evidence to working mechanisms. For example, our previous work (2015) found that third-grade students' conceptual understanding about water (e.g., atmospheric, hydrological, and geospheric components of the water cycle) improved over the course of a modeling-based unit, in which they had opportunities to construct, revise, and evaluate diagrammatic models of the water cycle. Regarding the epistemic features of modeling practice, the third graders were able to identify key factors (e.g., temperature change, gravity) and process sequences (e.g., water moving from sky to the ground, and then back to the sky), which were critical to establish cause-effect relationships in their reasoning about hydrologic phenomena.

\subsection{System models}

Another prevalent type of model in science education is a system model that describes a system in terms of its components and interactions. A system model is particularly useful in predicting the properties and behaviors of a whole system when changes occur. For instance, a food web is considered a system model in that it describes the predator and prey relationships among species within an ecological system. This model can predict the behavior of the ecological system if one species in the food chain changes. In contrast to a mechanistic model, a system model does not offer as much in the way of explanation or justification regarding why certain relationships exist between components (e.g., why do butterflies eat nectar from flowers?). Rather, the strength of a system model lies in the relational reasoning based on the interacting components and its predictive power about the system outcomes (e.g., what happens to the butterfly population if the number of flowers 
decreases in the area?). The difference is in part due to the distinct epistemic aims of the two types of models. While mechanistic models serve to unpack the causal mechanisms of why phenomena occur, system models aim to predict the behaviors of the systems under study without necessarily knowing all the causal step-by-step processes involved across all multi-level subsystems that are too complex and too dynamic for learners to represent.

Indeed, learning about systems is challenging, and much prior research has been done to promote system learning through modeling (Dickes \& Sengupta, 2013; Fortus et al., 2019; Hmelo-Silver et al., 2007; Stratford et al., 1998; Zangori et al., 2017). Hmelo-Silver and Pfeffer (2004) argued that it was productive to engage learners in constructing conceptual representations that highlight the structural, behavioral, and functional aspects of the system. While structures refer to elements of a system, behaviors refer to mechanisms of how the structures of a system achieve their functions. For example, in a human respiratory system, a main function is to supply oxygen to provide energy, which is fulfilled through the behaviors of ribs (structure) moving outward so that air can flow into the lungs (structure). Breaking down complex systems into the structural, behavioral, and functional levels may "aid learners in the process of making the implicit functions and behaviors of a system explicit," (p. 136), which are essential for understanding complex systems, especially for biological systems composed of interacting structure-function relationships. Furthermore, for a complex system involving nonlinear relationships (e.g., feedback loops), a computerbased modeling tool such as NetLogo (Wilensky \& Reisman, 2006) is often employed to help explore the aggregative or emergent system behaviors that are otherwise challenging to comprehend as "the properties and behaviors of the whole system can be very different from those of any of its parts" (National Research Council, 2012, p. 92). Computer-based learning environments afford students with opportunities to make predictions about the system by manipulating variables/parameters associated with key components and running simulations based on the rules they set up upfront. They can also help students recognize the limitations of system models: they only represent certain aspects of the target system and are limited in their predictions due to the assumptions and approximations inherent in the models.

\subsection{Mathematical/Data Models}

In the field of science education, mathematical/data modeling involves developing and using models derived from empirical data through scientific investigations that quantify and measure certain attributes of the phenomena (Lehrer \& Schauble, 2004; Malvern, 2000; Manz et al., 2020; Uhden et al., 2012). Mathematical/data models can take a variety of representational forms including plotted diagrams, histograms, and mathematical equations. Consider, for instance, Newton's second law of motion, $\mathrm{F}=$ ma. The equation mathematically describes the cause-and-effect relationship between force and changes in motion: the acceleration of an object is directly proportional to the magnitude of the net force acting on the object. It enables learners to explain and predict a wide range of phenomena about motion (e.g., a free-falling object). Therefore, one major epistemic goal of mathematical/data models is to build towards a quantitative understanding about the key causal relationships embedded in the underlying phenomena or systems.

Another epistemic goal of mathematical/data models is to help students make sense of the natural world through understanding the process of empirical experimentations and the associated fundamental mathematical/statistical concepts (e.g., sampling, distribution, and probability). This is so because conducting scientific experimentations requires students 
to discover patterns from data, measure those patterns, and then represent them using the language and symbols of mathematics. The coupling of mathematical/statistical concepts and scientific knowledge is critical for promoting scientific understanding because knowledge about mathematics/statistics is important to comprehend certain scientific topics and the inquiry processes, but it is often nonintuitive and challenging for students to apprehend when studied alone. For example, in the seminal work of Lehrer and Schauble (2012), a class of fifth grade students were engaged in a semester-long integrated curricular unit in which they used the idea of distribution to model and reason about plant growth. In the unit, students first determined what attributes of plants to measure (e.g., height) in order to answer their questions (e.g., did fertilizer or light affect plant growth?). Students then tried different ways to represent data as they developed understanding about the concept of distribution, which later helped them reason about plant growth, whether the observed differences in data were contributed by structural differences or by mere chance due to random sampling. Lehrer and Schauble (2012) further argued that "the starting place for education should be with the world and the problem it presents, rather than with the models themselves" (p. 636). In other words, in order to make data modeling practice meaningful, students need to think critically about what and how to measure, how to analyze and represent data, and what inferences to make about the properties of the phenomena, as opposed to simply learning about the final forms of the models and the underlying assumptions.

Note that we do not intend to claim that all scientific models fall into one of these three types or that they are necessarily exclusive of each other. For instance, a system model (e.g., a model about a specific ecosystem) may include behaviors at certain sublevels that resembles a mechanistic model (e.g., plants' photosynthesis and transpiration processes). However, the purpose of our categorization is to help teachers and students recognize that a range of epistemic goals can be achieved through modeling. The science classroom community should make decisions about what epistemic goals to prioritize for their model building: whether to explain the invisible step-by-step causal mechanisms (mechanistic models), to predict outcomes of a complex system (system models), or to quantitatively making sense of the underlying causal relationships (mathematical/data models).

\section{Socio-scientific Models}

As we previously mentioned, we use the term "socio-scientific models" to refer to representations that take social factors into consideration for the purposes of illustrating, explaining, and predicting complex socio-scientific issues or systems. It is important to note that the social factors do not refer to the social or cultural aspects of scientific knowledge (Galili, 2018), which is an important dimension of the nature of science. Rather, they refer to the social dimensions of an issue (e.g., history, economy, culture). As such, socioscientific models are multidisciplinary in nature. We suggest a distinction between scientific and socio-scientific models in recognition of the multidisciplinary nature of socioscientific models, and this is consistent with language that has been used to differentiate between scientific argumentation and socio-scientific argumentation (Sadler \& Donnelly, 2006). Like the situation with modeling, a key difference in scientific and socio-scientific arguments is the evidentiary standards used for identifying and evaluating evidence leveraged for the support of the argumentative claims. In short, the standards for scientific evidence used to support an argument are necessarily different than evidence standards for 
an argument based on ethical reasoning. Promoting an understanding of the differences in the kinds of evidence one uses in support of their arguments (and models) is educationally significant (Evagorou \& Osborne, 2013).

While the notion of socio-scientific models has not been explored much in the field of science education, this multidisciplinary modeling approach (which we contend is analogous to "causal loop diagrams" or "system diagrams") has been applied and studied in many other disciplines (Buchholz et al., 2007; Fairweather, 2010; Gray et al., 2017; Joffe \& Mindell, 2006; Voinov \& Bousquet, 2010). For example, Joffe and Mindell (2006) developed a medical model that links changes in health outcomes to transport policies. From the model, we can tell that each transport policy can have indirect effects on multiple health outcomes. One major advantage of this type of model is that it integrates a wide variety of information/data from different disciplinaries (e.g., policy, sociology, public health) into a single theoretical schema that can serve as a decision-making tool for solving practical problems. Therefore, we posit that this type of model can be particularly useful in negotiating complex societal issues as it allows students to draw connections between scientific knowledge and other social dimensions that are relevant in their decision-making processes, but not captured by scientific models.

In our prior work, we found that high school students were able to think systematically about the societal issue of regulating e-cigarettes with the support of socio-scientific models (Ke et al., 2020a). Figure 1 is an example of a socio-scientific model one group of students created during class. In the model, the group focused on the impacts of "no advertisement (of vaping product)" on different stakeholders including teens, parents, and companies that make vaping products. In particular, we found that students viewed their socio-scientific models as tools that scaffolded their examination of how e-cigarette regulations could impact the overall system associated with the issue. The students who created these models suggested that they would not otherwise have considered many of the system dimensions in their decision-making. We argue that, by developing and using socioscientific models, students are provided with opportunities to link scientific knowledge to the broader social contexts, which can in turn help them make informed decisions on SSI

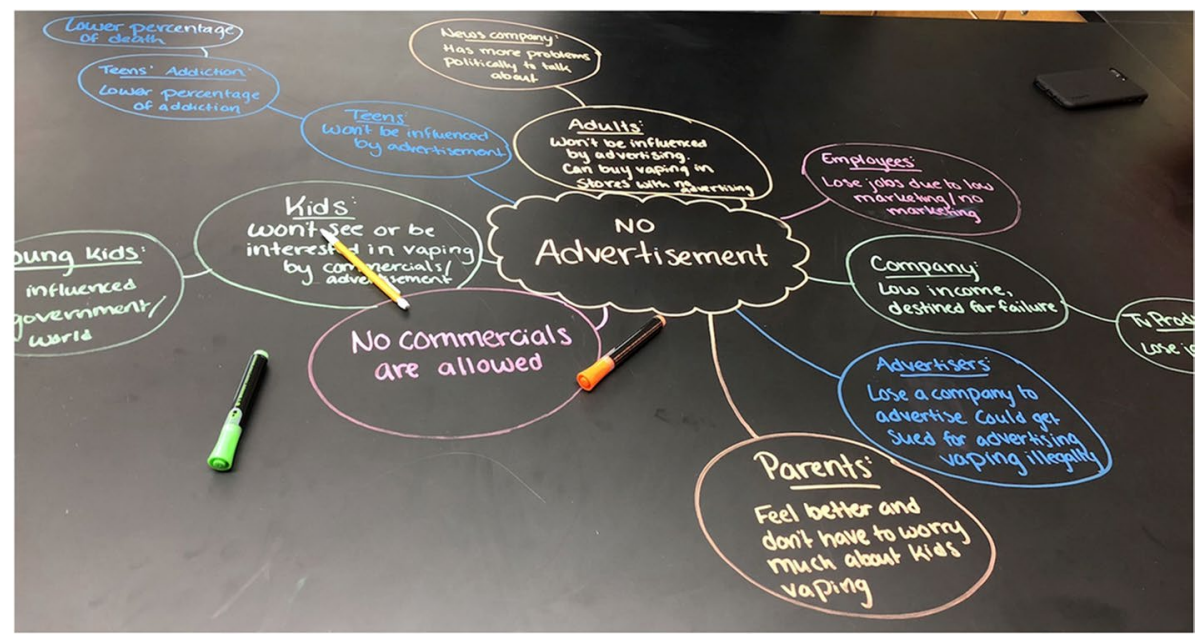

Fig. 1 A student group model for the regulation of vaping from Ke et al. (2020a) 
they face in their everyday lives. These links between science knowledge and other social dimensions are critical for developing students' scientific literacy as they help make science usable. In the following section, we use COVID-19 as an example to illustrate how a multiple-model approach may support student learning about the pandemic and promote scientific literacy as an overarching goal.

\section{Exemplar Multiple Models in the Context of COVID-19}

COVID-19 is the most significant and immediate issue that students are experiencing, and it is imperative for science educators to support students not only in understanding the science aspects of the virus, but more importantly, in responding to the pandemic as responsible members of the global community. So how can developing and using multiple models help achieve the goal? To answer the question, we present a combination of scientific models and socio-scientific models in this section. It is important to reiterate that we view models as epistemic tools that support students in making sense of phenomena or systems, as opposed to end products that students should conform to. As such, we value developing simplified models, or even false models that are in conflict of canonical scientific knowledge in science classrooms. Those simplified models may be later modified in light of new evidence collected, which we argue is a key aspect of modeling practice that students must engage in order to have a deep understanding of how science works. Next, we characterize the exemplar models of COVID-19 in terms of their epistemic purposes and affordances to demonstrate how they can be meaningfully incorporated in science classrooms.

First, it is helpful for students to explain how the virus infects the human body by developing a mechanistic model (see an example in Fig. 2). While the mechanistic model in Fig. 2 is not specific to SARS-CoV-2, it is something that students may come up with based on their existing knowledge about the structure of viruses and human cells. This generic model can be further revised if additional information about SARS-CoV-2 (e.g., the shape of the virus, the ACE2 receptor, the organs and cells it affects) is provided to students. Moreover, the mechanistic model with the step-by-step explanatory processes can explain a number of questions related to SARS-CoV-2 about which students may wonder. For example, based on the mechanistic model, students can explain how a drug designed to create a decoy for the receptor of SARS-CoV-2 or to disrupt the processes associated with
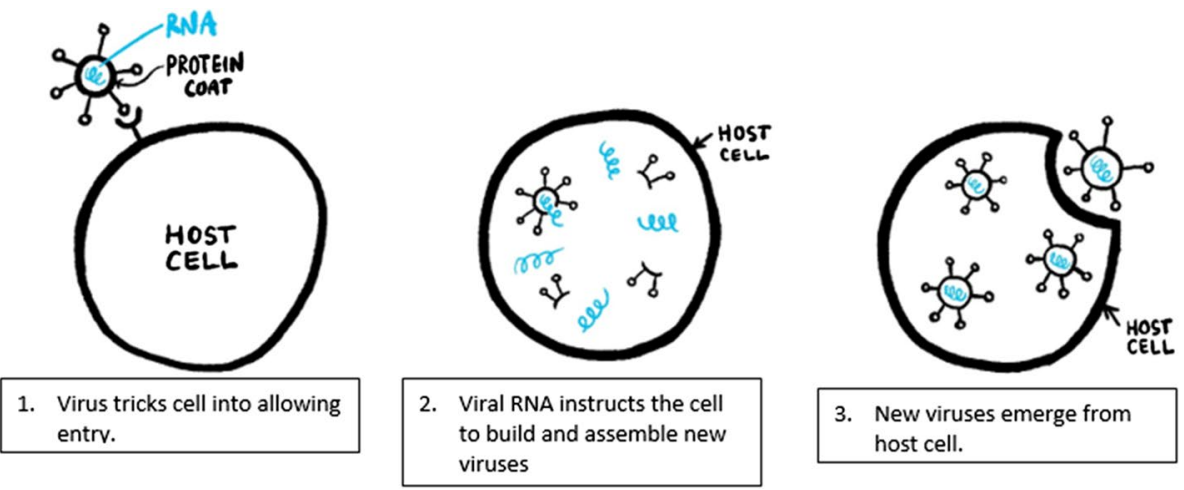

3. New viruses emerge from host cell.

Fig. 2 A mechanistic model of viral cell entry (unpublished diagram created by RJ Platto, 2020) 
the packaging and reassembly of the virus might work. Similarly, students can develop a mechanistic model of how SARS-CoV-2 is transmitted from person to person to explain how and why wearing a mask can help control the spread of the virus.

In addition to the mechanisms of viral infection and transmission, it is also important for students to understand how contagious COVID-19 is and what it looks like at the aggregated population level. To this end, a computer-based system modeling tool such as a NetLogo simulation is an appropriate way for students to explore the emergent system behavior as they are able to manipulate relevant variables. The outcome of the simulations could help students determine the impacts of different factors (e.g., level of social distancing and population density) on the spread of the virus. For instance, students can use the model to predict how much a low level of social distancing within a densely populated area can increase viral spread. Figure 3 presents a screenshot of a recently developed NetLogo simulation of the impacts of social distancing on the spread of a virus in a population (Kelter, 2020). Pedagogically, it is essential for teachers to emphasize the assumptions (e.g., the infection rates) associated with the simulation software so that students can have a better understanding of the limitations of their predictions.

From a mathematical/data modeling point of view, the notion of exponential growth is an important concept to make sense of the contagiousness of COVID-19. Therefore, an instructional emphasis on the idea of exponential growth with the aids of numerical and graphic expressions (see Fig. 4), coupled with an examination of the real data about the confirmed cases of COVID-19, can be a powerful way for students to understand viral spread and reproduction rates $\left(R_{0}\right)$ that can be otherwise nonintuitive. For example, with the knowledge of exponential growth and $R_{0}$, students can calculate $R_{0}$ for a given data set and determine whether differences exist between ethnicity groups within a certain area. Figure 4 presents an interface for a model created by our team for use by high school teachers and students to explore $R_{0}$ and changes in viral spread based on adjustments to $R_{0 .}$ Note that the mathematical model in Fig. 4 is simplified in the sense that it does not take into account the rate of recovery from COVID-19 and deems the population in a certain area to

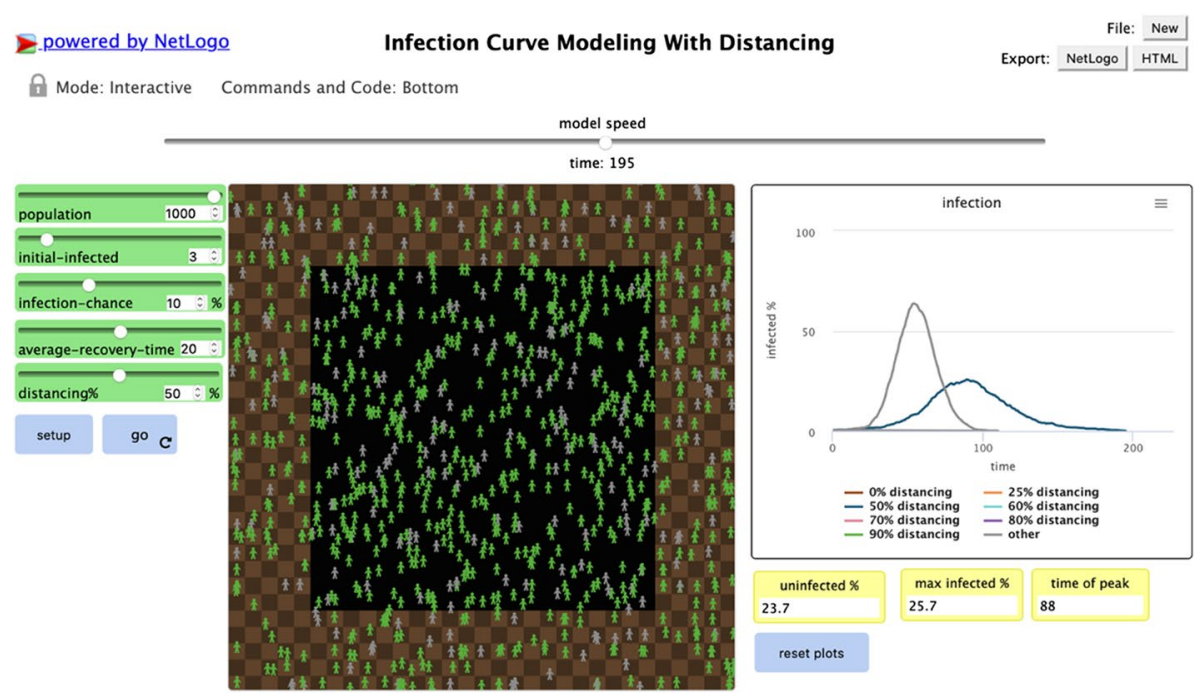

Fig. 3 A computer-based system model of infection rates simulated by NetLogo 


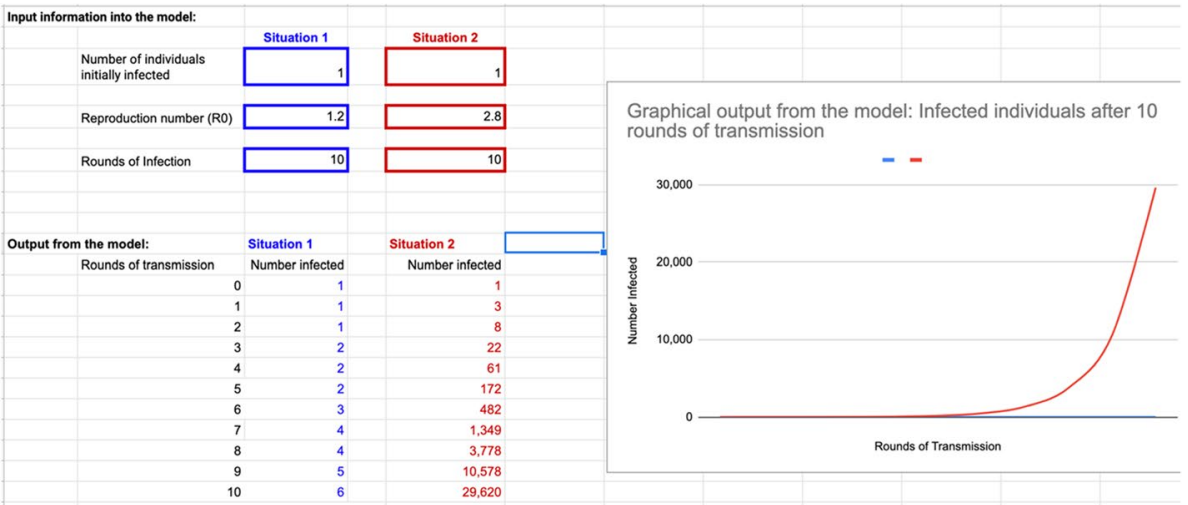

Fig. 4 An instructional activity of mathematical modeling on COVID-19

be unlimited. However, the simplification affords students the opportunities to understand the nonintuitive concept of exponential growth in the context of viral spread with the aid of data visualization. Once students have developed a good understanding of the rate of viral spread with the exponential growth assumption, they could compare their hypothesis with real data to critically examine how their mathematical models could be improved to better fit the reality.

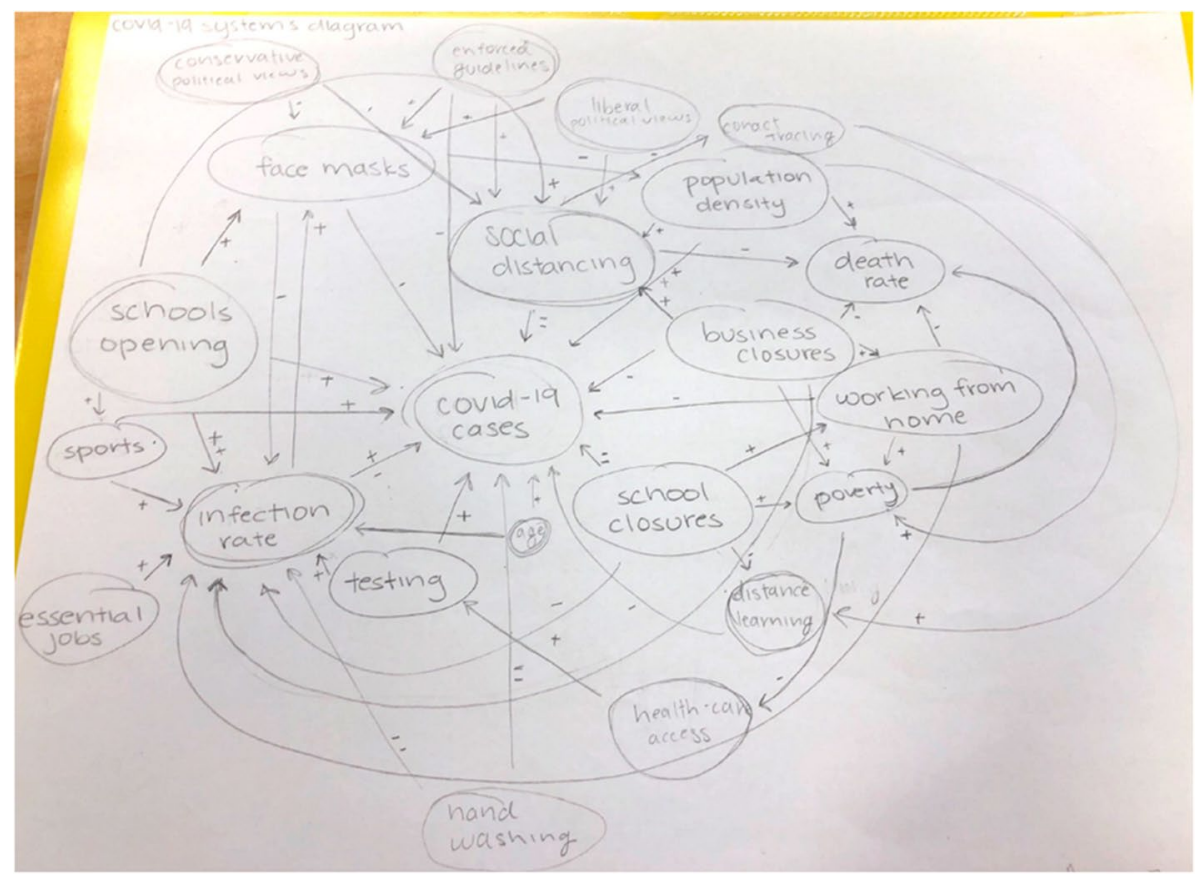

Fig. 5 A student socio-scientific model about COVID-19 
With respect to socio-scientific models, it is crucial for students to understand how COVID-19 is relevant to different sectors of the society (e.g., economy, politics, public health). Also, it is important for students to recognize that their personal decision-making could impact other elements in the system related to the issue. For example, Fig. 5 is an exemplar student socio-scientific model created in the COVID-19 unit that our research team co-developed with participating teachers. In the model, the student highlighted how a "conservative political view" could lead to a lower "use of face masks," which will increase the "infection rate." It is also interesting to note that the relationship between "social distancing" and "COVID-19" is science-based, which could be informed and justified by the two scientific models we previously discussed regarding viral spread. In fact, this aligns with one of the goals for developing and using socio-scientific models: to help students transfer the scientific knowledge to their reasoning about the complex issue. Some may argue that socio-scientific models do not hold much scientific information, and therefore should not be included in science classrooms - this is consistent with perspectives that researchers have observed among practicing science teachers (Sadler et al., 2006; Tidemand $\&$ Nielsen, 2017). However, we contend that the socio-scientific modeling activity could give students a reason to explore scientific ideas. Furthermore, socio-scientific system models can provide a tool for helping students figure out how scientific ideas might link to other dimensions relevant to the issue and essential for informing decisions/positions. While this potential connection between science decision-making is lauded as an important outcome of scientific literacy, traditional disciplinary-focused science instruction has a terrible track record of actually supporting this linkage (Zeidler, 2014).

To summarize, in this section, we present four types of model that we argue students should develop and use to better understand the science behind COVID-19 as well as how to respond to the pandemic in their everyday life. A reasonable question is how does this proposal compare to ideas represented in other science curricular materials around COVID-19? In fact, incorporating modeling in COVID-19 learning materials is not in itself an innovative idea. For example, in online instructional material about COVID-19 (COVID-19: The Story Behind the Science, n.d.) funded by the US National Science Foundation, a number of representations have been highlighted such as the structure of a virus, the spread of the virus, and the process of entry, replication, and exit of the virus in human body. Then the question becomes, how does our proposal contribute to the field?

While the Story Behind the Science (SBS) materials share our vision of scientific literacy that values making science relevant in daily lives, we contend that our proposal differs in two important ways. First, our proposed modeling activities position students as cognitive agents who actively develop and use different types of models to build their own knowledge. Therefore, one essential design feature we advocate is to consider what model simplifications need to be made so that they are accessible to students. Consequently, the four models we present are all simplified in varying degrees to meet students' learning needs. By contrast, while the representations in SBS materials are all scientifically robust and sound, it is not clear how students are able to develop or use models similar to those represented in the materials. Second, in order for students to negotiate complex societal issues such as COVID-19, we emphasize the importance of taking into account the social dimensions of the issue by developing and using socio-scientific models. This is because, despite our interest in promoting scientific literacy and belief that decisions on complex issues such as COVID-19 should be driven by science, we recognize that other social factors can play a critical role in people's decision-making as well. In other words, we do not assume that students will spontaneously adopt a position on complex issues primarily based on science once they have learned the science aspects of the issues. In comparison, 
while decision-making about COVID-19 is also a key component in the SBS materials, it mainly focuses on science-based decisions without much attention to the other social dimensions such as economic impacts, as illustrated by the proposed case study (i.e., To mask or not to mask: This is the scientific question). Our point here is not to critique other learning materials about COVID-19, many of which have merits beyond the scope of this paper (e.g., the focus on misrepresentation of science in media and the dialogical processes of how students develop positions on COVID-19 in the SBS case). Rather, it is to show how our perspectives on incorporating modeling in SSI teaching and learning, and specifically the proposal for a combination of scientific models and socio-scientific models, add value to our current understanding of teaching science through complex issues to promote scientific literacy.

\section{Discussion and Conclusion}

What are the key factors that we as science educators need to consider when designing classroom instruction with a multiple-model approach? First, it is important to be explicit about the epistemic aims for different types of models. As we discussed earlier, modeling is an epistemic practice, and different models, whether scientific or socio-scientific, serve different epistemic purposes. For instance, when developing a mechanistic model of viral infection, it is advisable for teachers to emphasize the goal of explaining the phenomena, as opposed to only focusing on the representational structures of the host cell and virus. Similarly, when engaging students in socio-scientific modeling activities, students should be encouraged to use their scientific knowledge and consider how that knowledge fits with the larger social context. In essence, teachers should help students see the epistemic goals as well as the affordances and constraints of different modeling activities, rather than the final forms of different types of models, in order to make the practice meaningful.

Second, given that there are multiple models students are expected to develop and use, it is critical for teachers to consider the sequencing of modeling activities. However, there is no simple answer to the question of what order should modeling experiences be presented. SSI span multiple scientific phenomena and both scientific and social systems contribute to the difficulty of the question. For example, should students engage in scientific modeling first to develop scientific knowledge and skills necessary for reasoning about the system underlying the issue via socio-scientific models, or is it more productive for students to engage in socio-scientific modeling first so that they know what aspects of science dimension relate to the issue they need to further explore? The problem is further complicated by the fact that modeling involves different elements or stages including model construction, model revision, and model evaluation. While some modeling activities may be designed in a way that cuts across an entire unit so that students have the opportunities to engage in the whole modeling cycle (e.g., developing a mechanistic model of viral spread with two rounds of revisions in light of new evidence about SARS-CoV-2), others may be isolated classroom activities that only require students' engagement in one aspect of modeling practice (e.g., using the NetLogo simulation tool to explore the relationship between social distancing and infection rates). Indeed, the sequencing of different types of modeling activities is an empirical question that needs additional research. Future research should compare alternative hypotheses about the sequencing of modeling experiences and examine the impacts of differential sequencing on student learning. 
In conclusion, this paper proposes a new approach to SSI teaching and learning that involves developing and using multiple models. In particular, we argue that engagement in multiple scientific models promotes students' understanding about the phenomena relevant to the focal issue, and engagement in socio-scientific models helps students to use that scientific knowledge in the larger social contexts and reason about how interacting science and social factors may impact students' positions on the complex issue. This approach is significant in bridging disciplinary knowledge and everyday decision-making and has important implications for teaching science for scientific literacy.

Funding This research was supported by the National Science Foundation under Grant No. 2023088 -RAPID: Responding to and Emerging Epidemic through Science Education (REESE). Any opinions, findings, and conclusions or recommendations expressed in this material are those of the authors and do not necessarily reflect the views of the National Science Foundation.

\section{Declarations}

Conflict of interest Li Ke, Troy Sadler, Laura Zangori, and Patricia Friedrichsen declare that they have no conflict of interest.

\section{References}

Ainsworth, S. (2008). The educational value of multiple representations when learning complex scientific concepts. In John K. Gilbert, M. Reiner, \& M. Nakhleh (Eds.), Visualization: Theory and practice in science education (pp. 191-208). Springer Netherlands. https://doi.org/10.1007/978-1-4020-5267-5_9.

American Association for the Advancement of Science. (1993). Benchmarks for scientific literacy. Oxford University Press.

Bokulich, A. (2011). How scientific models can explain. Synthese, 180(1), 33-45. https://doi.org/10.1007/ s11229-009-9565-1.

Brown, B. A., Reveles, J. M., \& Kelly, G. J. (2005). Scientific literacy and discursive identity: a theoretical framework for understanding science learning. Science Education, 89(5), 779-802. https://doi.org/10. 1002/sce.20069.

Buchholz, T. S., Volk, T. A., \& Luzadis, V. A. (2007). A participatory systems approach to modeling social, economic, and ecological components of bioenergy. Energy Policy, 35(12), 6084-6094. https://doi.org/ 10.1016/j.enpol.2007.08.020.

Cartwright, N. (1999). The dappled world: a study of the boundaries of science. Cambridge University Press.

Chinn, C. A., Buckland, L. A., \& Samarapungavan, A. (2011). Expanding the dimensions of epistemic cognition: Arguments from philosophy and psychology. Educational Psychologist, 46(3), 141-167. https://doi.org/10.1080/00461520.2011.587722.

Clement, J. (2008). The role of explanatory models in teaching for conceptual change. In S. Vosniadou (Ed.), Handbook of research on conceptual change. Lawrence Erlbaum Associates Inc.

COVID-19: The story behind the science. (n.d.). Retrieved December 7, 2020, from https://storybehindthes cience.org/covid19.html.

DeBoer, G. E. (2000). Scientific literacy: another look at its historical and contemporary meanings and its relationship to science education reform. Journal of Research in Science Teaching, 37(6), 582-601. https://doi.org/10.1002/1098-2736(200008)37:6<582::AID-TEA5>3.0.CO;2-L.

Dickes, A. C., \& Sengupta, P. (2013). Learning natural selection in 4th grade with multi-agent-gased computational models. Research in Science Education, 43(3), 921-953. https://doi.org/10.1007/ s11165-012-9293-2.

Duschl, R. A., Schweingruber, H. A., \& Shouse, A. W. (Eds.). (2007). Taking science to school: Learning and teaching science in grade $K-8$. National Academies Press. 
Evagorou, M., \& Osborne, J. (2013). Exploring young students' collaborative argumentation within a socioscientific issue. Journal of Research in Science Teaching, 50(2), 209-237. https://doi.org/10.1002/tea. 21076.

Fairweather, J. (2010). Farmer models of socio-ecologic systems: application of causal mapping across multiple locations. Ecological Modelling, 221(3), 555-562. https://doi.org/10.1016/j.ecolmodel.2009.10. 026

Forbes, C. T., Zangori, L., \& Schwarz, C. V. (2015). Empirical validation of integrated learning performances for hydrologic phenomena: 3rd-grade students' model-driven explanation-construction. Journal of Research in Science Teaching, 52(7), 895-921.

Ford, M. (2008). Grasp of practice as a reasoning resource for inquiry and nature of science understanding. Science \& Education, 17(2), 147-177. https://doi.org/10.1007/s11191-006-9045-7.

Fortus, D., Kubsch, M., Bielik, T., Krajcik, J., Lehavi, Y., Neumann, K., et al. (2019). Systems, transfer, and fields: Evaluating a new approach to energy instruction. Journal of Research in Science Teaching, 56(10), 1341-1361. https://doi.org/10.1002/tea.21556.

Frederiksen, J. R., \& White, B. Y. (2002). Conceptualizing and constructing linked models: Creating coherence in complex knowledge systems. In P. Brna, M. Baker, K. Stenning, \& A. Tiberghien (Eds.), The role of communication in learning to model (pp. 69-96). Erlbaum.

Galili, I. (2018). Scientific knowledge as a culture: A paradigm for meaningful teaching and learning of science. In M. R. Matthews (Ed.), History, philosophy and science teaching: New perspectives (pp. 203-233). Springer International Publishing. https://doi.org/10.1007/978-3-319-62616-1_8.

Gilbert, J. K., \& Osborne, R. J. (1980). The use of models in science and science teaching. European Journal of Science Education, 2(1), 3-13. https://doi.org/10.1080/0140528800020103.

Gray, R., \& Rogan-Klyve, A. (2018). Talking modelling: Examining secondary science teachers' modellingrelated talk during a model-based inquiry unit. International Journal of Science Education, 40(11), 1345-1366. https://doi.org/10.1080/09500693.2018.1479547.

Gray, S., Jordan, R., Crall, A., Newman, G., Hmelo-Silver, C., Huang, J., et al. (2017). Combining participatory modelling and citizen science to support volunteer conservation action. Biological Conservation, 208, 76-86. https://doi.org/10.1016/j.biocon.2016.07.037.

Harrison, A. G., \& Treagust, D. F. (2000). A typology of school science models. International Journal of Science Education, 22(9), 1011-1026. https://doi.org/10.1080/095006900416884.

Hmelo-Silver, C. E., \& Pfeffer, M. G. (2004). Comparing expert and novice understanding of a complex system from the perspective of structures, behaviors, and functions. Cognitive Science, 28(1), 127-138. https://doi.org/10.1207/s15516709cog2801_7.

Hmelo-Silver, C. E., Marathe, S., \& Liu, L. (2007). Fish swim, rocks sit, and lungs breathe: Expert-novice understanding of complex systems. Journal of the Learning Sciences, 16(3), 307-331. https://doi.org/ 10.1080/10508400701413401.

Jimenez-Aleixandre, M.-P. (2002). Knowledge producers or knowledge consumers? Argumentation and decision making about environmental management. International Journal of Science Education, 24(11), 1171-1190. https://doi.org/10.1080/09500690210134857.

Joffe, M., \& Mindell, J. (2006). Complex causal process diagrams for analyzing the health impacts of policy interventions. American Journal of Public Health, 96(3), 473-479. https://doi.org/10.2105/AJPH. 2005.063693.

Ke, L., \& Schwarz, C (2021). Supporting students' meaningful engagement in scientific modeling through epistemological messages: A case study of contrasting teaching approaches. Journal of Research in Science Teaching, 58(3), 335-365. https://doi.org/10.1002/tea.21662.

Ke, L., Sadler, T. D., Zangori, L., \& Friedrichsen, P. (2020a). Students' perceptions of engagement in socioscientific issue-based learning and their appropriation of epistemic tools for systems thinking. International Journal of Science Education, 42(8), 1339-1361. https://doi.org/10.1080/09500693.2020.17598 432020.1759843 .

Ke, L., Zangori, L., Sadler, T., \& Friedrichsen, P. (2020b). Integrating scientific modeling and socio-scientific reasoning to promote scientific literacy. In W. Powell (Ed.), Socio-scientific issue-based instruction for scientific literacy development. IGI Global.

Kelter, J. (2020). Agent-based model of virus spread. Retrieved from https://www.jacobkelter.com/infec tion-model/.

Knuuttila, T. (2005). Models, representation, and mediation. Philosophy of Science, 72(5), 1260-1271. https://doi.org/10.1086/508124.

Kolst $\varnothing$, S. D. (2001). Scientific literacy for citizenship: tools for dealing with the science dimension of controversial socioscientific issues. Science Education, 85(3), 291-310. https://doi.org/10.1002/sce.1011.

Krajcik, J., Reiser, B. J., Sutherland, L. M., \& Fortus, D. (2012). IQWST: Investigating and questioning our world through science and technology. Activate Science. 
Latour, B. (1999). Pandora's hope: Essays on the reality of science studies. Cambridge, MA: Harvard University Press

Laugksch, R. C. (2000). Scientific literacy: A conceptual overview. Science Education, 84(1), 71-94. https://doi.org/10.1002/(SICI)1098-237X(200001)84:1<71::AID-SCE6>3.0.CO;2-C.

Lehrer, R., \& Schauble, L. (2004). Modeling natural variation through distribution. American Educational Research Journal, 41(3), 635-679. https://doi.org/10.3102/00028312041003635.

Lehrer, R., \& Schauble, L. (2006). Scientific thinking and science literacy: Supporting development in learning in contexts. In W. Damon, R. M. Lerner, K. A. Renninger, \& I. E. Sigel (Eds.), Handbook of child psychology (6th ed., Vol. 4). Wiley.

Lehrer, R., \& Schauble, L. (2012). Seeding evolutionary thinking by engaging children in modeling its foundations. Science Education, 96(4), 701-724. https://doi.org/10.1002/sce.20475.

Levins, R. (1966). The strategy of model building in population biology. American Scientist, 54(4), $421-431$.

Levinson, R. (2008). Promoting the role of the personal narrative in teaching controversial socio-scientific issues. Science \& Education, 17(8), 855-871. https://doi.org/10.1007/s11191-007-9076-8.

Louca, L. T., \& Zacharia, Z. C. (2012). Modeling-based learning in science education: Cognitive, metacognitive, social, material and epistemological contributions. Educational Review, 64(4), 471-492. https:// doi.org/10.1080/00131911.2011.628748.

Malvern, D. (2000). Mathematical models in science. In John K. Gilbert \& C. J. Boulter (Eds.), Developing models in science education (pp. 59-90). Springer. https://doi.org/10.1007/978-94-010-0876-1_4.

Manz, E. (2012). Understanding the codevelopment of modeling practice and ecological knowledge. Science Education, 96(6), 1071-1105. https://doi.org/10.1002/sce.21030.

Manz, E., Lehrer, R., \& Schauble, L. (2020). Rethinking the classroom science investigation. Journal of Research in Science Teaching, 57(7), 1148-1174. https://doi.org/10.1002/tea.21625.

National Research Council. (2012). A framework for K-12 science education: practices, crosscutting concepts, and core ideas. National Academies Press.

Nersessian, N. J. (2008). Creating scientific concepts. MIT Press.

NGSS Lead States. (2013). Next generation science standards: for states, by states. National Academies Press.

Oh, P. S., \& Oh, S. J. (2011). What teachers of science need to know about models: An overview. International Journal of Science Education, 33(8), 1109-1130. https://doi.org/10.1080/09500693.2010. 502191.

Passmore, C., Gouvea, J. S., \& Giere, R. (2014). Models in science and in learning science: focusing scientific practice on sense-making. In M. R. Matthews (Ed.), International handbook of research in history, philosophy and science teaching (pp. 1171-1202). Springer Netherlands. http://link.springer. com/chapter/10.1007/978-94-007-7654-8_36.

Peel, A., Zangori, L., Friedrichsen, P., Hayes, E., \& Sadler, T. (2019). Students' model-based explanations about natural selection and antibiotic resistance through socio-scientific issues-based learning. International Journal of Science Education, 41(4), 510-532. https://doi.org/10.1080/09500693.2018.15640 84.

Roberts, D. A. (2007). Scientific literacy/science literacy. In S. K. Abell \& N. G. Lederman (Eds.), Handbook of research on science education (pp. 729-780). Lawrence Erlbaum Associates.

Sadler, T. D. (2004). Informal reasoning regarding socioscientific issues: A critical review of research. Journal of Research in Science Teaching, 41(5), 513-536. https://doi.org/10.1002/tea.20009.

Sadler, T. D., \& Donnelly, L. A. (2006). Socioscientific argumentation: The effects of content knowledge and morality. International Journal of Science Education, 28(12), 1463-1488. https://doi.org/10.1080/ 09500690600708717.

Sadler, T. D., \& Zeidler, D. L. (2009). Scientific literacy, PISA, and socioscientific discourse: Assessment for progressive aims of science education. Journal of Research in Science Teaching, 46(8), 909-921. https://doi.org/10.1002/tea.20327.

Sadler, T. D., Amirshokoohi, A., Kazempour, M., \& Allspaw, K. M. (2006). Socioscience and ethics in science classrooms: Teacher perspectives and strategies. Journal of Research in Science Teaching, 43(4), 353-376. https://doi.org/10.1002/tea.20142.

Sadler, T. D., Barab, S. A., \& Scott, B. (2007). What do students gain by engaging in socioscientific inquiry? Research in Science Education, 37(4), 371-391. https://doi.org/10.1007/s11165-006-9030-9.

Sadler, T. D., Foulk, J. A., \& Friedrichsen, P. J. (2017). Evolution of a model for socio-scientific issue teaching and learning. International Journal of Education in Mathematics, Science and Technology, 5(1), 75-87. https://doi.org/10.18404/ijemst.55999.

Sadler, T. D., Friedrichsen, P., \& Zangori, L. (2019). A framework for teaching for socio-scientific issue and model based learning (SIMBL). Educação e Fronteiras/Education and Borders, 9(25), 8-26. 
Schwarz, C. V., Reiser, B. J., Davis, E. A., Kenyon, L., Achér, A., Fortus, D., et al. (2009). Developing a learning progression for scientific modeling: Making scientific modeling accessible and meaningful for learners. Journal of Research in Science Teaching, 46(6), 632-654. https://doi.org/10.1002/tea.20311.

Stieff, M., Scopelitis, S., Lira, M. E., \& Desutter, D. (2016). Improving representational competence with concrete models. Science Education, 100(2), 344-363. https://doi.org/10.1002/sce.21203.

Stratford, S. J., Krajcik, J., \& Soloway, E. (1998). Secondary students' dynamic modeling processes: Analyzing, reasoning about, synthesizing, and testing models of stream ecosystems. Journal of Science Education and Technology, 7(3), 215-234. https://doi.org/10.1023/A:1021840407112.

Stroupe, D. (2014). Examining classroom science practice communities: How teachers and students negotiate epistemic agency and learn science-as-practice. Science Education, 98(3), 487-516. https://doi.org/ $10.1002 /$ sce. 21112 .

Tidemand, S., \& Nielsen, J. A. (2017). The role of socioscientific issues in biology teaching: From the perspective of teachers. International Journal of Science Education, 39(1), 44-61. https://doi.org/10. 1080/09500693.2016.1264644.

Uhden, O., Karam, R., Pietrocola, M., \& Pospiech, G. (2012). Modelling mathematical reasoning in physics education. Science \& Education, 21(4), 485-506. https://doi.org/10.1007/s11191-011-9396-6.

Voinov, A., \& Bousquet, F. (2010). Modelling with stakeholders. Environmental Modelling \& Software, 25(11), 1268-1281. https://doi.org/10.1016/j.envsoft.2010.03.007.

Weisberg, M. (2007). Three kinds of idealization. The Journal of Philosophy, 104(12), 639-659. https://doi. org/10.5840/jphil20071041240.

Wilensky, U., \& Reisman, K. (2006). Thinking like a wolf, a sheep, or a firefly: Learning biology through constructing and testing computational theories-An embodied modeling approach. Cognition and Instruction, 24(2), 171-209. https://doi.org/10.1207/s1532690xci2402_1.

Windschitl, M., Thompson, J., \& Braaten, M. (2008). Beyond the scientific method: model-based inquiry as a new paradigm of preference for school science investigations. Science Education, 92(5), 941-967. https://doi.org/10.1002/sce.20259.

Zangori, L., \& Forbes, C. T. (2014). Scientific practices in elementary classrooms: Third-grade students' scientific explanations for seed structure and function. Science Education, 98(4), 614-639. https://doi. org/10.1002/sce.21121.

Zangori, L., Peel, A., Kinslow, A., Friedrichsen, P., \& Sadler, T. D. (2017). Student development of modelbased reasoning about carbon cycling and climate change in a socio-scientific issues unit. Journal of Research in Science Teaching, 54(10), 1249-1273. https://doi.org/10.1002/tea.21404.

Zeidler, D. L. (2014). Socioscientific issues as a curriculum emphasis: theory, research and practice. In S. K. Abell \& N. G. Lederman (Eds.), Handbook of research on science education (pp. 697-726). Routledge.

Zeidler, D. L., Sadler, T. D., Simmons, M. L., \& Howes, E. V. (2005). Beyond STS: A research-based framework for socioscientific issues education. Science Education, 89(3), 357-377. https://doi.org/10. 1002/sce. 20048

Publisher's Note Springer Nature remains neutral with regard to jurisdictional claims in published maps and institutional affiliations. 